\title{
Correspondence
}

\section{Blood pressure control in stroke patients}

\section{What should the consulting neurologist advise?}

To the Editor: I find it remarkable that the article by Messerli et al. ${ }^{1}$ refers to "the blood pressure." Anyone in practice has had the common experience of having several blood pressure readings with a wide range during a several-hour period; for example, it is common for the systolic blood pressure to be $40 \mathrm{~mm} \mathrm{Hg}$ lower, in a patient with $\mathrm{PD}$, when measured early in the morning recumbent vs when measured during peak-dose dyskinesia upright.

The weakest link in the argument for clinical neurology practitioners is the representative blood pressure with respect to treating patients with hypertension. If a 6 -hour to 24 -hour averaged blood pressure measurement device was available, there would not be much question about the academician's conclusion that patients with hypertension should be treated more aggressively.

Stuart R. Snider, MD, Tucson, AZ

Reply from the Author: Dr. Snider is correct in pointing out that there is not something like one blood pressure for each patient. Blood pressure, like any other hemodynamic measurement, is extremely variable and fluctuates from heartbeat to heartbeat, from inspiration to expiration, from day to night, from winter to summer, from rest to exercise, etc. The fact that it can be measured much easier than measurements such as cardiac output, ejection fraction, pulmonary wedge pressure, etc. should not, however, diminish its value. Blood pressure, when measured under standard conditions, such as sitting in the physician's office, has been shown time and again in numerous large prospective studies and in cohorts, such as Framingham, to be a powerful independent prognosticator for stroke, heart attack, and congestive heart failure. Conceivably, 24-hour ambulatory blood pressure monitoring may provide more information and, therefore, be a better surrogate endpoint than clinic blood pressure. ${ }^{2}$
A good example of this is the Heart Outcomes Prevention Evaluation (HOPE) study in which the benefits of ramipril on stroke and heart attacks were claimed to be relatively independent of blood pressure. ${ }^{3}$ Unfortunately, little information is available with regard to blood pressure measurements, which apparently were done without proper standardization. However, 24-hour ambulatory blood pressure monitoring done in a subset of 38 patients clearly showed that blood pressure was substantially lower in patients on ramipril than in those on placebo. ${ }^{4}$ This would indicate that in the HOPE Study there was no need to invoke ancillary benefits of angiotensinconverting enzyme inhibitors in general or ramipril in particular to explain the reduction in morbidity and mortality. ${ }^{5}$ Until a more accurate tool, such as 24-hour ambulatory blood pressure monitoring becomes routinely available, clinic blood pressure properly measured will remain a valuable clinical tool that should be treasured by practicing physicians and neurologists alike.

Franz H. Messerli, MD, New Orleans, LA

Copyright $@ 2003$ by AAN Enterprises, Inc.

\section{References}

1. Messerli FH, Hanley DF, Jr, Gorelick PB. Blood pressure control in stroke patients. What should the consulting neurologist advise? Neurology 2002;59:23-25.

2. Staessen JA, Thijs L, Fagard R, et al. Predicting cardiovascular risk using conventional vs ambulatory blood pressure in older patients with systolic hypertension. Systolic Hypertension in Europe Trial Investigators. JAMA 1999;282:539-546.

3. Effects of ramipril on cardiovascular and microvascular outcomes in people with diabetes mellitus: results of the HOPE study and MICROHOPE substudy. Heart Outcomes Prevention Evaluation Study Investigators. Lancet 2000;355:253-259.

4. Svensson P, de Faire U, Sleight P, Yusuf S, Ostergren J. Comparative effects of ramipril on ambulatory and office blood pressures: a HOPE Substudy. Hypertension 2001;38:E28-E32.

5. Messerli FH, White WB, Staessen JA. If only cardiologists did properly measure blood pressure-BP recordings in daily practice and clinical trials. J Am Coll Cardiol 2002 (in press).

\section{Ocular flutter in a patient with intracranial hypertension following cerebral venous thrombosis}

To the Editor: Ploner et al. ${ }^{1}$ have again documented the rare association of ocular flutter with raised intracranial pressure and resolution with lowering of the intracranial pressure. They cite the case reported by Cogan $^{2}$ of a child (case B-9) with ocular flutter who had progressive hydrocephalus and "cerebral atrophy" as determined by air study and died but did not have a postmortem exam, but have failed to refer to our first clinical and pathologic report ${ }^{3}$ of a child with progressive hydrocephalus who had temporary resolution of the eye movement disorder following reduction of intracranial pressure with return of the eye movement disorder as the intracranial pressure increased again. Our patient died as a result of shunt surgery, and postmortem exam showed no other pathology in the brainstem structures, besides the dilated ventricular system and a large cisterna magna. We had postulated that the eye movement disorder was secondary to pressure on the cerebellum by a large cisterna magna or dilated fourth ventricle as previous autopsy reports had suggested a dysfunction of the cerebellum as the cause. ${ }^{4}$

Taranath Shetty, MD, FRCP(C), Providence, $R I$

Reply from the Authors: We are grateful for Dr. Shetty's comments on our manuscript, which underline the role of intracranial hypertension in central eye movement disorders. We are aware of their case, which describes an association of opsoclonus and raised intracranial pressure. ${ }^{3}$ However, in their report, there were several additional oculomotor deficits that were not present in our case. Moreover, although there appears to be considerable overlap between the etiology of opsoclonus and ocular flutter, these eye movement disorders are nevertheless clinically distinct. ${ }^{5}$ To our knowledge, it is not yet entirely clear whether both conditions always share the same pathophysiology. ${ }^{5}$ These points should be taken into consideration when both cases are compared.

\section{C.J. Ploner, MD, A. Kupsch, MD, PhD, Berlin, Germany}

Copyright $\odot 2003$ by AAN Enterprises, Inc.

\section{References}

1. Ploner CJ, Kupsch A. Ocular flutter in a patient with intracranial hypertension following cerebral venous thrombosis. Neurology 2002;59:959.

2. Cogan DG. Ocular dysmetria: Flutter-like oscillations of eyes, and opsoclonus. Arch Opthal 1954;51:318-335.

3. Shetty T, Rosman NP. Opsoclonus in hydrocephalus. Arch Opthal 1972; 88:585-589.

4. Moe PG, Nellhaus G. Infantile polymyoclonia: Opsoclonus syndrome and neural crest tumours. Neurology 1970;20:756-764.

5. Leigh RJ, Zee DS. The neurology of eye movements, 3rd ed. New York: Oxford University Press, 1999.
Clinical features of frontotemporal dementia due to the intronic tau $10^{+16}$ mutation

To the Editor: We read with great interest the article by Janssen et al. ${ }^{1}$ regarding clinical features seen in nine apparently sepa- rately ascertained kindreds with frontotemporal dementia and parkinsonism (FTDP-17) harboring the same intronic $10^{+16}$ tau mutation. They attempted to correlate variations in phenotype observed in their families with $A P O E \in 4$ allele status. DNA was available from 14 family members. No correlation was found be- 
Table Clinical presentation of PPND family members with and without the apolipoprotein $\mathrm{E} \epsilon 4$ allele

\begin{tabular}{lcc}
\hline Characteristic & $\epsilon 4-/-$ & $\epsilon 4-/+$ \\
\hline No. of patients & 13 & 8 \\
Mean age at onset, y* & 41.9 & 46.1 \\
Mean disease duration, $\mathrm{y}^{*}$ & 9.3 & 8.3 \\
Initial presentation, n & & \\
$\quad$ Parkinsonism & 7 & 5 \\
Personality changes & 1 & 1 \\
$\quad$ Dementia & 2 & 0 \\
$\quad$ Parkinsonism/personality changes & 2 & 1 \\
$\quad$ Personality changes/dementia & 1 & 0 \\
$\quad$ Parkinsonism/dementia & 0 & 1 \\
Autopsy result & & \\
$\quad$ Amyloid deposition in the brain, n/total & $0 / 9$ & $0 / 4$ \\
$\quad$ autopsied & &
\end{tabular}

* Difference not significant $(p>0.05)$.

PPND = pallido-ponto-nigral degeneration

tween $A P O E$ genotype and age at symptomatic disease onset, disease duration, or degree of brain atrophy.

We longitudinally follow one of the largest FTDP-17 kindreds, the pallido-ponto-nigral degeneration (PPND) family, which has another tau mutation, specifically at N279K. ${ }^{2,3}$ This family also shows variation in clinical presentation. We genotyped 21 affected members from this kindred to determine their $A P O E$ status and compared the age at symptomatic disease onset, disease duration, and initial clinical presentation in patients with and without the $\epsilon 4$ allele. Similarly to Janssen et al., ${ }^{1}$ we found no correlation between these clinical variables and the $A P O E-\epsilon 4$ allele (table). Furthermore, we evaluated variability in clinical presentation in four major branches of the PPND family in relation to APOE- $\epsilon 4$ allele status and again found no correlation. ${ }^{4}$ In the 13 patients from the PPND family who were autopsied, we found no amyloid deposition in the brain, although four of these patients had the $A P O E-\epsilon 4$ allele..$^{2,5}$ We agree with Janssen et al. ${ }^{1}$ that environmental or genetic factors other than the $A P O E-\epsilon 4$ allele status likely contribute to the differences seen in the clinical presentation of FTDP-17 families.

Y. Tsuboi, MD, R.J. Uitti, MD, M. Baker, BSc, M.L. Hutton, $\mathrm{PhD}$, Z.K. Wszolek, MD, Jacksonville, FL

Copyright $\odot 0$ by AAN Enterprises, Inc.

\section{References}

1. Janssen JC, Warrington EK, Morris HR, et al. Clinical features of frontotemporal dementia due to the intronic tau $10^{+16}$ mutation. Neurology 2002;58:1161-1168.

2. Wszolek ZK, Pfeiffer RF, Bhatt MH, et al. Rapidly progressive autosomal dominant parkinsonism and dementia with pallido-ponto-nigral degeneration. Ann Neurol 1992;32:312-320.

3. Tsuboi Y, Uitti RJ, Delisle MB, et al. Clinical features and disease haplotypes of individuals with the N279K tau gene mutation: a comparison of the pallidopontonigral degeneration kindred and a French family. Arch Neurol 2002;59:943-950.

4. Wszolek ZK, Tsuboi Y, Farrer MJ, Uitti RJ, Hutton ML. Hereditary tauopathies and parkinsonism. Adv Neurol 2002;91:153-163.

5. Reed LA, Schmidt ML, Wszolek ZK, et al. The neuropathology of a chromosome 17-linked autosomal dominant parkinsonism and dementia ("pallidoponto-nigral degeneration”). J Neuropathol Exp Neurol 1998;57:588-601.

\section{Homocysteine, MTHFR $677 \mathrm{C} \rightarrow \mathrm{T}$ polymorphism, and risk of ischemic stroke: Results of a meta-analysis}

To the Editor: Unlike randomized controlled trials, metaanalysis of observational studies remains controversial because bias and confounding contribute to between-study heterogeneity. The meta-analysis by Kelly et al. ${ }^{1}$ is further complicated by other methodological shortcomings.

A meta-analysis of a continuous exposure should standardize the estimate of effect for a uniform change in that exposure. For example, other meta-analyses of total plasma homocysteine (tHcy) and cardiovascular disease have expressed the pooled odds ratio (OR) in terms of a 5 - $\mu$ mol change in tHcy. ${ }^{2,3}$ Kelly et al. ${ }^{1}$ state that it is clinically useful to express the risk of stroke associated with tHcy in a dichotomous manner. However, they do not state the chosen cut-off for defining hyperhomocysteinaemia. In the supplementary tables on the Neurology website, the definition of hyperhomocysteinaemia is different for each study. By combining estimates based on these different definitions, the authors have rendered their pooled effect estimate meaningless.

They also pooled studies based on the reported measure (e.g., ORs, hazard ratio, or arithmetic means) rather than on methodological rigour or study design. For example, case-control studies and nested case-control studies are pooled because they both report ORs. Case-control studies are subject to selection bias, whereas nested case-control studies, essentially an efficient use of prospective cohort data, are not. This is a logical source of possible heterogeneity between studies. In this scenario, it may be more appropriate to pool nested case-control studies and cohort studies. An OR from a nested case-control study is a close approximation to the true risk or hazard ratio, as long as there has been appropriate sampling of controls. Pooling, based on arithmetic means, selectively excluded valid analysis of studies of geometric means and again resulted in different study designs being combined. The authors also pooled estimates, which were adjusted for different confounders (table 4A), and omitted one major nested case control study ${ }^{4}$ the first "null" study, from two of their analyses (figure 4) without any justification.

It is tempting to pool numbers without thinking about impor- tant sources of heterogeneity between studies, particularly when underpowered statistical tests of heterogeneity show no effect. It would be more productive to examine these differences in detail using sensitivity analysis and meta- regression. ${ }^{5}$ This may provide insights into why results from observational studies of homocysteine and stroke are so different and help produce a more valid estimate rather than a potentially misleading one.

Una B. Fallon, MB, MA, MSc, MRCGP, Yoav Ben-Shlomo, MB, MSc, MRCP, FFPHM, Bristol, UK

Reply from the Authors: Drs. Fallon and Ben-Shlomo mainly address the second analysis in our paper. As we and others have emphasized, there are several decision-making points, which must be addressed when performing meta-analysis of observational data, and well-described caveats, which apply when interpreting the result. ${ }^{6}$ The didactic tone of their discussion is interesting, as no consensus exists in the field on a single standard methodology to resolve these decisions.

A primary aim of our analysis was to provide reliable summary estimates of tHcy- associated stroke risk, which could be clearly communicated to and applied by practicing physicians, and which were derived from studies in which cases were well-characterized The practical utility of previous analyses has been limited, as the results have been difficult to apply in a clinical context. In some cases, investigators have pooled studies of stroke with those of heart disease, or reported results in terms that are not readily communicated to clinicians and patients, such as the log-transformed or raw increase in OR per 1- or 5- $\mu \mathrm{mol} / \mathrm{L}$ increase in tHcy., ${ }^{2,7}$

When counseling patients, there are intuitive benefits to expressing disease risk associated with a continuous variable in terms of "high" or "normal" levels, as is commonly done with blood pressure and cholesterol. We summarized the relationship between tHcy and stroke risk in terms of the case-control difference in arithmetic mean and the OR. These measures have the advantages of being straightforward and readily interpreted in clinical practice and have been used in earlier similar analyses. ${ }^{8}$ As we emphasized in the text and Table 2, a disadvantage of this approach is that no consistent threshold for high tHcy has been 
applied across published studies. However, the differences in threshold values (most $12-20 \mu \mathrm{mol} / \mathrm{L}$ ) are of relatively little clinical significance when viewed in the context of the range of tHcy values $(>100 \mu \mathrm{mol} / \mathrm{L})$ associated with stroke in patients with acquired or inherited disorders of tHcy metabolism. ${ }^{9}$ The result is interpreted as an estimate of stroke risk in individuals with elevated tHcy in the mild or low-moderate range, as is common in the general population.

We agree that the OR from a nested case-control study approximates the hazard ratio from cohort studies. In the original manuscript submission, we combined cohort and nested case-control studies in a single analysis, but separated them by reported effect measure at the request of the reviewers. The combined pooled risk estimate of cohort and nested case-control studies was 1.5 (95\% CI $1.2,1.89, p<0.001$ ).

To facilitate the interpretation of our results, we minimized statistical manipulation of published data. As described in the Methods section, we excluded studies that reported geometric means, as the standard deviations may not be accurately calculated. The study by Alfthan et al. ${ }^{4}$ fulfilled inclusion criteria for the analysis of arithmetic means, but was excluded from our second analysis, as a dichotomous OR was not provided and could not be accurately derived. Detailed exploratory analyses of betweenstudy heterogeneity, while of theoretical interest, have limited clinical utility and were not a primary aim of our analysis.

P.J. Kelly, MB, MS, MRCPI, J. Rosand, MD, MS, V. Shih, MD, J. Kistler, MD, K.L. Furie, MD, MPH, Boston, $M A$

Copyright $\odot 0$ by AAN Enterprises, Inc.

\section{References}

1. Kelly PJ, Rosand J, Kistler JP, et al. Homocysteine, MTHFR $677 \mathrm{C} \rightarrow \mathrm{T}$ polymorphism, and risk of ischemic stroke: results of a meta-analysis Neurology 2002;59:529-536.

2. Ford ES, Smith SJ, Stroup DF, Steinberg KK, Mueller PW, Thacker SB. Homocyst(e)ine and cardiovascular disease: a systematic review of the evidence with special emphasis on case-control studies and nested casecontrol studies. Int J Epidemiol 2002;31:59-70.

3. Ueland PM, Refsum H, Beresford SA, Vollset SE. The controversy over homocysteine and cardiovascular risk. Am J Clin Nutr 2000;72: 324-332.

4. Alfthan G, Pekkanen J, Jauhiainen M, et al. Relation of serum homocysteine and lipoprotein(a) concentrations to atherosclerotic disease in a prospective Finnish population based study. Atherosclerosis 1994;106:9-19.

5. Egger M, Davey Smith G, Schneider M. Systematic reviews of observational studies. In: Egger M, Davey Smith G, Altman DG, eds. Systematic Reviews in Health Care. Meta-Analysis in Context. London: BMJ Publishing Group, 2001: 211-227.

6. Petitti DB. Meta-Analysis, Decision Analysis, and Cost-Effectiveness Analysis. Methods for Quantitative Synthesis in Medicine. $2^{\text {nd }}$ ed. New York, Oxford University Press, 2000

7. Brattstrom L, Wilcken DEL, Ohrvik J, Brudin L. Common methylenetetrahydrofolate reductase gene mutation leads to hyperhomocysteinemia but not to vascular disease. Circulation 1998;98:2520-2526.

8. Boushey CJ, Beresford S, Omenn GS, Motulsky AG. A quantitative assessment of plasma homocysteine as a risk factor for vascular disease: Probable benefits of increasing folic acid intakes. JAMA 1995;274:10491057.

9. Kelly PJ, Furie KL, Kistler JP, et al. Stroke in young patients with hyperhomocysteinemia due to cystathionine beta-synthase deficiency. Neurology (in press).

\section{Reduced inhibition within primary motor cortex in patients with poststroke focal motor seizures}

To the Editor: We read with interest the article by Kessler et al., ${ }^{1}$ who selected a subgroup of six patients with ischemic stroke in which the cortical silent period (CSP) after transcranial magnetic stimulation (TMS) was shortened by at least $25 \%$ in either the upper-or lower-affected limb compared with the unaffected side. Focal motor seizures occurred in five of these patients, whereas none of 76 control patients with normal or prolonged CSP developed poststroke seizures. As the CSP likely reflects $\mathrm{GABA}_{\mathrm{B}^{-}}$ mediated inhibitory mechanisms within the primary motor cortex,$^{2}$ the authors suggest that seizures following ischemic stroke may be due to a selective impairment of GABAergic interneurons at the epileptic focus. There are, however, some weaknesses in these findings. 1) From Table 2, it seems that significant intraindividual differences of CSP duration were found by using single trials as data samples. In contrast, no significant difference between the affected and the unaffected side would had been observed in either the first dorsal interosseous (FDI) or tibialis anterior if one had used the mean CSP duration of each subject to perform conventional parametric (paired sample student's $t$-test) or nonparametric (Wilcoxon signed rank test) statistic analysis within the whole group of six patients. Moreover, in Patient 1, who had focal motor seizures in the left arm, the CSP was prolonged in the affected FDI compared with the right one. 2) In two of five patients, the lag time between stroke and first seizure was longer than the follow-up period for the control patients with normal or prolonged CSP after stroke.

A number of previous papers, which are not cited by Kessler et al., ${ }^{1}$ showed that the CSP could be prolonged in patients with partial seizures involving the motor cortex or generalized epilepsy. ${ }^{3-7}$ Epileptic conditions are characterized by pathophysiologic mechanisms leading to seizures and interictal compensatory phenomena. ${ }^{8}$ As a given epileptic syndrome can be due to different processes, we hypothesize that the CSP can be either reduced or prolonged, if the underlying neural circuits are involved in the epileptogenesis or in the interictal compensatory mechanisms. Although the present data do not draw conclusions, the findings reported by Kessler et al. ${ }^{1}$ suggest that further studies using similar homogeneous case series may help clarify this point.

Massimo Cincotta, Alessandra Borgheresi, Fabrizio Balestrieri, Gaetano Zaccara, Florence, Italy
Reply from the Authors: We appreciate the comments made by Cincotta et al. who point out some essential aspects of our study. Regarding their first main point, the intraindividual variability of the CSP determined in 10 single trials was fairly low, whereas the interindividual variation of CSP duration was indeed quite high, as has been reported previously in the literature. ${ }^{9}$ Unfortunately, group comparisons in either the FDI or tibialis anterior (TA), as suggested by Cincotta et al, were impossible because of the small sample sizes $(n=3)$. Nevertheless, there was a significant group difference in CSP duration when comparing the means of all affected muscles vs their unaffected counterpart $(\mathrm{n}=6, \mathrm{~W}=-21.0$, $p<0.03$; Wilcoxon signed rank test). Furthermore, to determine the potential of this method for assessing the individual risk for a stroke patient to develop poststroke seizures, it seemed more appropriate to show significant differences of CSP duration individually than to merely demonstrate a group effect.

We are of course aware of the investigations cited by Cincotta et al. extending and underscoring an important issue also raised in our paper, namely the obviously conflicting results brought forth by previous noninvasive investigations of cortical excitability in patients with epilepsy. There are a number of potential clinical (e.g., type and duration of epilepsy, and antiepileptic therapy) and methodological (e.g., threshold, CSP, and paired-pulse technique) reasons as to why this issue is still unresolved. Furthermore, the exact physiology of the CSP is hitherto not completely understood, but our assumption that a reduced CSP indicates impaired intracortical inhibition is certainly in line with earlier findings of a reduced intracortical inhibition using paired-pulse paradigms in patients with focal epilepsies..$^{10,11}$ We were able to show an association of a markedly reduced CSP and the occurrence of poststroke seizures. This may indeed suggest that symptomatic poststroke epilepsy be characterized by a pathophysiologic mechanism that is quite distinct from that in cryptogenic motor cortex epilepsy. Along with Cincotta et al., we hope that this case series will stimulate further investigations along this line.

Kirn R. Kessler, MD, Alfons Schnitzler, MD, PhD, Joseph Classen, MD, PhD, Reiner Benecke, MD, PhD, Frankfurt, Germany

Copyright $\odot 0$ by AAN Enterprises, Inc.

\section{References}

1. Kessler KR, Schnitzler A, Classen J, Benecke R. Reduced inhibition within primary motor cortex in patients with poststroke focal motor seizures. Neurology 2002;59:1028-1033.

2. Siebner HR, Dressnandt J, Auer C, Conrad B. Continuous intrathecal baclofen infusions induced a marked increase of the transcranially 
evoked silent period in a patient with generalized dystonia. Muscle Nerve 1998;21:1209-1215

3. Classen J, Witte OW, Schlaug G, et al. Epileptic seizures triggered directly by focal transcranial magnetic stimulation. Electroenceph Clin Neurophysiol 1995;94:19-25.

4. Cincotta M, Borgheresi A, Lori S, Fabbri M, Zaccara G. Interictal inhibitory mechanisms in patients with cryptogenic motor cortex epilepsy: a study of the silent period following transcranial magnetic stimulation. Electroencephalogr Clin Neurophysiol 1998;107:1-7.

5. Ertas NK, Gul G, Altunhalka A, Kirbas D. Cortical silent period following transcranial magnetic stimulation in epileptic patients. Epileptic Disord 2000;2:137-140.

6. Macdonell RA, King MA, Newton MR, et al. Prolonged cortical silent period after transcranial magnetic stimulation in generalized epilepsy. Neurology 2001;57:706-708.

7. Cincotta M, Borgheresi A, Benvenuti F, et al. Cortical silent period in two patients with meningioma and preoperative seizures: a pre- and postsurgical follow-up study. Clin Neurophysiol 2002;113:597-603.

8. Engel J Jr. Inhibitory mechanisms of epileptic seizure generation. In: Fahn S, Hallett M, Lüders HO, Marsden CD, eds. Advances in Neurology, vol 67. Negative Motor Phenomena. Philadelphia: LippincottRaven Publishers, 1995:157-171.

9. Fritz C, Braune HJ, Pylatiuk C, et al. Silent period following transcranial magnetic stimulation: a study of intra- and inter-examiner reliability. Eletrocencaphalogr Clin Neurophysiol 1997;105:235-241.

10. Fong JKY, Werhahn KJ, Rothwell JC, et al. Motor cortex excitability during the silent period in focal and generalized epilepsy. J Physiol (Lon) $1993 ; 459: 468 \mathrm{P}$.

11. Inghilleri M, Mattia D, Berardelli A, Manfredi M. Asymmetry of cortical excitability revealed by transcranial stimulation in a patient with focal motor epilepsy and cortical myoclonus. Electroencephalogr Clin Neurophysiol 1998;109:70-72.

\section{Corrections}

\section{Relating anatomy to function in Alzheimer's disease}

\section{Neuropsychological profiles predict regional neuropathology 5 years later}

In the article "Relating anatomy to function in Alzheimer's disease: Neuropsychological profiles predict regional neuropathology 5 years later" (Neurology 1998;50:979-985) by Kanne et al., the psychometric means ( \pm SD) for Associate Learning (bold) in table 2 on p. 981 should be $12.4 \pm 3.4$ for the control group, $8.8 \pm 3.4$ for the group with very mild DAT, and $5.7 \pm 2.7$ for the group with mild DAT. The correct table is:

Table 2 Psychometric means ( $\pm S D$ ) and demographicsa for the nondemented control subjects, very mild DAT, and mild DAT groups

\begin{tabular}{lccc}
\hline & Control subjects & Vrey mild DAT & Mild DAT \\
\hline Age, y & $75.7 \pm 10.3$ & $74.1 \pm 8.5$ & $73.8 \pm 8.6$ \\
Education & $14.0 \pm 3.4$ & $13.0 \pm 3.4$ & $12.2 \pm 3.5$ \\
Gender (M/F) & $98 / 163$ & $92 / 91$ & $86 / 138$ \\
Information & $19.9 \pm 4.6$ & $15.1 \pm 5.7$ & $9.7 \pm 5.2$ \\
Boston Naming & $52.7 \pm 7.0$ & $44.4 \pm 12.0$ & $33.7 \pm 14.3$ \\
Logical Memory & $8.1 \pm 2.8$ & $4.3 \pm 2.7$ & $1.9 \pm 1.7$ \\
Associate Learning & $\mathbf{1 2 . 4} \pm \mathbf{3 . 4}$ & $\mathbf{8 . 8} \pm \mathbf{3 . 4}$ & $\mathbf{5 . 7} \pm \mathbf{2 . 7}$ \\
Benton: Copy & $9.4 \pm 1.3$ & $9.1 \pm 1.6$ & $7.3 \pm 2.7$ \\
Trailmaking A & $50.3 \pm 26.0$ & $70.2 \pm 39.2$ & $108.3 \pm 50.5$ \\
Block Design & $28.5 \pm 8.1$ & $22.2 \pm 9.8$ & $12.0 \pm 9.6$ \\
Digit Symbol & $42.5 \pm 12.5$ & $31.7 \pm 13.6$ & $17.0 \pm 13.3$ \\
Digit Span Forward & $6.7 \pm 1.2$ & $6.1 \pm 1.2$ & $5.8 \pm 1.3$ \\
Word Fluency & $28.3 \pm 9.5$ & $23.4 \pm 9.7$ & $14.7 \pm 9.3$ \\
Mental Control & $7.2 \pm 1.9$ & $5.9 \pm 2.4$ & $4.4 \pm 2.7$ \\
\hline
\end{tabular}

Psychometric tests are scored such that greater scores indicate better performance with the exception of Trailmaking A, for which higher scores indicate slower performance.

$\mathrm{DAT}=$ dementia of the Alzheimer type.

\section{The chemokine receptor CCR5 deletion mutation is associated with MS in HLA-DR4-positive Russians}

In the article "The chemokine receptor CCR5 deletion mutation is associated with MS in HLA-DR4-positive Russians" (Neurology 2002;59:1652-1655) by Favorova et al., there was an error in two of the column headings in table 3. The heading of the second

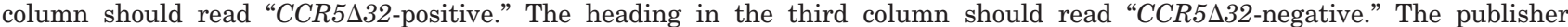
apologizes for this error. 


\section{Neurology}

\section{To: Neuropsychological profiles predict regional neuropathology 5 years later: Relating anatomy to function in Alzheimer's disease \\ Neurology 2003;60;528 \\ DOI 10.1212/WNL.60.3.528}

\section{This information is current as of February 11, 2003}

\section{Updated Information \&}

Services

Permissions \& Licensing

Reprints including high resolution figures, can be found at: http://n.neurology.org/content/60/3/528.1.full

Information about reproducing this article in parts (figures,tables) or in its entirety can be found online at:

http://www.neurology.org/about/about_the_journal\#permissions

Information about ordering reprints can be found online:

http://n.neurology.org/subscribers/advertise

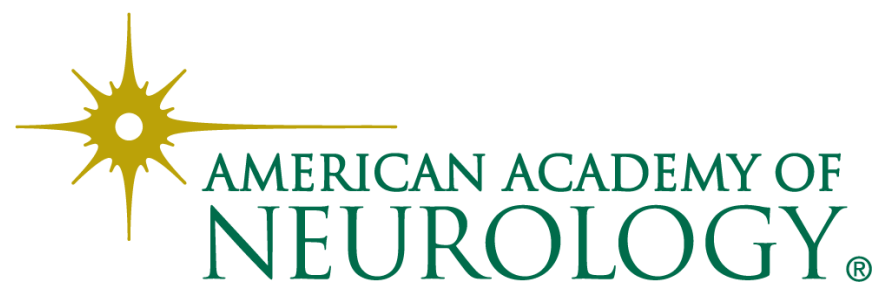

